\title{
Managing the Pandemic of Obesity: Siding with the Fox or the Hedgehog?
}

\author{
Michael Myslobodsky ${ }^{a, b} \quad$ Loring J. Ingraham ${ }^{c}$ \\ ${ }^{a}$ Howard University Graduate School, Washington, \\ ${ }^{b}$ Clinical Brain Disorders Branch, NIMH/National Institutes of Health, Bethesda, \\ ${ }^{\mathrm{C}}$ Professional Psychology Program, George Washington University, Washington, USA
}

\section{Key Words}

Obesity - Treatment - Prevention - Public health . Cognitive therapy

\section{Summary}

Obesity is a major public health problem of pandemic proportion. Despite its high prevalence and widespread distribution (consistent with a common underlying etiology), clinical psychologists and primary care physicians routinely approach the problem with individualized but often ineffective treatments like psychotherapy and pharmacotherapy, or propose alterations to specific components of the 'toxic environment', cultural influences, and psychosocial factors purported to cause overeating. This paper presents an alternative perspective and proposes a potential framework for assisting health professionals in developing rational approaches to education about and preventive treatment of obesity based on the role of factors in early life that contribute to personality and behavior and which over time lead to obesity and its maintenance.

\section{Introduction}

Although the current pandemic of obesity is said to have been driven by environmental factors, in reality the latter are dependably fueled by some simple personal choices: the inability to alter the food selection (e.g., more fat and sugar) and the size of intake (e.g., bigger portions), and a decrease in physical activity in the everyday routine. Those who wish to reduce weight are traditionally torn between two opposite tendencies: pharmacotherapy and lifestyle changes, mostly di- rected by cognitive-behaviorally oriented therapies. None is fully successful, mostly because no therapy is ever as nuanced as the paths leading to obesity, environmentally, psychologically or genetically.

Genetics of obesity that one day might hopefully provide therapeutically relevant insights is not a theory, but rather a body of ideas, models, and methods directed to predict, estimate, understand and optimize the search of genes and proteins controlling different aspects of feeding behaviors. None of the monogenic variants of obesity is of importance for its garden variety [1], so that patients with varied etiologies have been lumped together by the 'thrifty genes' theory of obesity [2] into a pool of genetic victims of natural selection. The latter is a popular cliché that maintains that obesity is a 'spillover' of aggressive 'thriftiness' from a domain in which it was beneficial in our remote past. An important corollary of this idea is that natural selection must have favored a 'thrifty behavioral phenotype' to match the thrifty metabolic machinery to secure the 'survival of the fittest' $[3,4]$. The major component of human environment is social interaction, such that commenting on the 'thrifty' hypothesis, Hockaday and Yajnik [3] indicated that genetic control of the ability to maintain weight in the face of environmental disadvantages would affect many domains needed to succeed in securing scarce food: motivation, drive, reward dependence, and expectancies when processing environmental and mnemonic signals.

Perhaps, such determination in actively pursuing environmental niches and seizing the right opportunity at the right time, as well as in manipulating the environment or resisting it, was envisioned by Bateson [5] who coined the term envirotype. Envirotype may be defined as 'selfish phenotype' uncoupling it from its 'selfish genes', or as culturally based cognitive pragmatics, the 'software' of the mind [6]. In the social domain, it is in keeping with Bandura's notion of 'reciprocal determinism' [7]. The latter implies that the world and individual behaviors

\section{KARGER}

Fax +497614520714

Information@Karger.de

www.karger.com (c) 2009 S. Karger GmbH, Freiburg

Accessible online at:

www.karger.com/ofa 
mold one another; that the way people think, feel and behave informs and alters their environment; that environmental influences and cognitive and other personal factors (self-beliefs) create interactions that result in a triadic reciprocity of cognition, behavior and environment [8]. Whether this metaphor is accepted or not, the advantage of the envirotype is in sensitizing us to the dictum of a French poet, Rene Char (1907-1988): 'Develop your legitimate strangeness' since the tenacity of the famished is expected to morph into diverse neuropsychological 'individual pathway(s) to obesity' [9] that have been targeted by cognitive-behavioral therapies. This emphasis on diverse neuropsychological and lifestyle factors reflects a profound ambivalence in weight management between the hope of future discoveries of the safe and efficacious anti-obesity agents as opposed to a reliance on control of the gamut of environmental events and self-control, neither of which can be easily phrased in the language of molecular machinery.

In the following, some aspects of this neuropsychological reductionism are reviewed in order to show that individually focused behavioral remediation of obesity is unlikely to contain the current epidemic.

\section{Neuropsychological Reductionism}

\section{'Tyranny of the Urgent': Reward Discounting}

In keeping with terms of evolutionary ecology [10], individuals tend to control consumption impulses if convinced that a delay of gratifying the whim is worthy. Eating behaviors of the Paleolithic hunter were dependent on the 'myopic' rule that eating should not be delayed since food supply was never granted. Uncertainty leads to an error in the original goal value and a degree of its 'markdown' associated with numerous personal and extrapersonal circumstances. Such gradual devaluation of reinforcers with time is labeled time discounting. Time discounting refers to any reason for caring less about the future, from a diminished reinforcement value of expected benefits due to changing tastes or to health attrition [11]. It may conceivably describe individual variability in eating behaviors, particularly concerning delayed penalty of overeating. Accordingly, greedy 'myopic' impulses are in keeping with 'thrifty genes' programming, and have the advantage of drawing attention to the utility of immediately available smaller and less rewarding victuals when the rate of feeding is random [12]. Stephens [13] observed that birds presented with a choice of getting a small food reward immediately or waiting a short moment for a bigger one could not be trained to wait, even after a thousand repetitions. The work may apply to humans, he suggested, because taking rewards without hesitation may have paid off for our foraging ancestors [12], as memorialized in the aphorism 'a bird in hand is worth two in the bush'.

People do not randomly choose food items since preference stems from efforts to maximize pleasure [14], and there is a reluctance to change established behaviors in order to comply with therapeutic demands. Operationally, addiction is defined through behaviors initiated 'to produce pleasure and to provide relief from internal discomfort' [15]. Dependence on eating may thus be paraphrased after the Diagnostic and Statistical Manual of Mental Disorders(DSM)-III-R criteria regarding psychoactive substance dependence, as '... a cluster of cognitive, behavioral, and physiologic symptoms that indicate that the person has impaired control over eating and continues it in undesirable quantity despite adverse consequences.' Thus defined, however, 'food addiction' is a feat of medicalization in that this characterization justifies the conviction that we are all fundamentally gamblers living in a chancy world [16].

The similarity between compulsive overeating and food addiction, and parallels of both to addiction disorders such as substance abuse, is frequently pointed out [17]. That is, addiction sets in when expectations (drives) are fulfilled or even exceeded, thus leading to a pleasurable experience. In turn, both categories of individuals are compared to compulsive gamblers. In fact, in a structured psychological environment, healthy adult women with obesity as reflected in high BMI manifest an impaired performance at computerized gambling tasks [18-20]. Although decisions to take a bet in a gambling game are not directly related to the food domain, they do provide support for the hypothetical link between obesity and neuronal processes, which regulate one's ability to inhibit short-term rewards when the long-term consequences are deleterious [19]. Choices made by obese individuals in the gambling task are believed to be reminiscent of a 'decisionmaking disorder' of patients with a prefrontal cortex defect that implies difficulties in 'veto' functions, e.g., inhibition of excessive food intake [20]. Patients with ventromedial prefrontal damage do behave as if they are insensitive to future social penalties, being primarily guided by immediate rewards that ultimately lead to a net financial loss, and do not develop anticipatory autonomic responses [21] (see, however, alternative interpretations in ref. [22]). Evidence for impairments in eating behavior following isolated prefrontal lesions acquired in adulthood is still lacking.

\section{Loss of 'Experience of Ownership'}

Although cognitive-behavioral group treatment programs emphasize stimulus-control techniques and reinforcement techniques, and help with cognitive restructuring, self-observation is at the heart of these therapeutic techniques [23]. However, the judgment of potential effects of eating may be less self-referential in obese individuals. Self-reported dietary records or accounts of physical activity can be erratic in obese individuals [24-28] as though showing that misbelief (self-deception) is beneficial for their coping style [29]. Up to $46 \%$ of people who are overweight or obese underestimate what they eat by about 300-400 kcal/day, studies show. Such miscalculation can easily thwart an individual's weight loss efforts [30]. 
How can we reconcile those erroneous self-perceptions with the fact that people are generally concerned with what they eat? Perhaps they do not have access to their episodic memory. Alternatively, as with patients with ventromedial prefrontal damage, they have deficient metacognitive faculties (metamemory, insight, and awareness of one's own mental states) or they understand diet dilemmas and restrictions when the problem is spelled out verbally, but fail in real-life settings. Since successful restraint (will-power) is believed to require cognitive efforts [31], another reason might be that people are less attentive to the quantity of food consumed. Preconsciously, they choose to avoid food-related imagery by engaging strategically with diverse aspects of their environment and, in so doing, disrupt the unity of their experience [32].

The unity of self is experienced when our mind supplies us with timely previews of actions that turn out to be accurate when we observe the actions that ensue [33]. Gain of weight provides neither an accurate nor a timely feedback. In most cases, it is immensely gradual and delayed. A common cliché is that butter added to a cake or a cookie contains more energy than a similar weight of an explosive, such as trinitrotoluene (TNT), except that the energy of butter is released slowly (through metabolism). Consequently, the causal effect of a couple of extra cookies a day may not be associated with the experience of authorship or ownership, i.e. the sense that weight gain a few years later was caused by one's own behavior.

\section{Magical Thinking}

The scenario of magical thinking, also known as the self-torturer puzzle of Warren Quinn [34], is a continuation of the previous theme. As the puzzle's scenario goes, a person is given a chance to collect a thousand dollars by self-delivery of electrical currents through a medical device implanted on his body. The current dial permits advancing just one setting a day or leaving it where it was and getting nothing. Such 'self-stimulation' could continue day by day for 10 years. The sensations were so mild initially that the 'player' felt as though the device is harmless. After a decade of so doing, the pain becomes much too great to bear. It follows from the moralistic Faustian logic of the puzzle that perfectly conscious and rational individuals, by accepting presumably innocuous and tempting rewarding contracts, would reach beyond the range of desirable outcomes. Andreou [35] explains that the 'self-torturer' is not alone in his predicament. The accumulation of trifling weight gain after ingesting a scoop of ice cream per week distributed over a few years could easily lead to a considerable weight gain in well-informed people. An often-cited example is that ingestion of only $8 \mathrm{kcal} /$ day more, expended over 30 years, could lead to an increase of $10 \mathrm{~kg}$ in body weight. Not many think of this increment when young, but that is the average amount of weight gained by American adults from 25 to 55 years of age [36]. Some individuals will not be convinced to diet or exercise because their overweight is a risk factor for somatic or neurodegenerative disorders that far beyond their prospective horizon. Even if risk is acknowledged, according to Weinstein's [37] seminal idea, people have a tendency to claim that one is less at risk than one's peers.

The self-torturer's paradox may be interpreted as a particular deficit in high-level planning routine when people cannot prepare themselves for future challenges or rather have difficulties to cognitively time travel in their episodic memory when planning for the future. Such ability entails the coupling of future-oriented executive operations or visualizing oneself in a specific future event while juxtaposing the future with relevant episodic memories. A model of such a process has been proposed elsewhere in discussing prospective memory or memory for intentions [38].

\section{Impulsiveness}

Many obese and weight-gaining people assert that their eating impulses escape their ability to control them [39]. That is why the construct of impulsivity (lack of cognitive restraint, disinhibition and disregard of planning, attentional and motor rashness) has gained interest as a sign of decision-making impairments in otherwise normal eating patterns as well as in eating-disordered populations. Impulsivity could secure higher fitness when competition is intense, but would put one at a disadvantage when competition is relaxed and slow exploration of potential options and their delay works well. The trait is singled out as a crucial personality characteristic for the development and maintenance, as well as treatment, of obesity $[40,41]$. It is most resistant to management as compared to other personality traits; it remains a dominant symptom after surgery for morbid obesity whereas other personality features gradually normalize in proportion to the magnitude of weight loss [42]. Obese women showed deficits in response inhibition on objective behavioral measures while they did not appear impulsive on self-report measures [43]. In laboratory studies, impulsivity might be easily validated by scoring the rate of commission errors (failures to withhold responses to nontarget stimuli) in versions of the continuous performance test (CPT). With regard to impulsivity, it should be noted that the majority of impulses for eating are not hunger related [44], justifying a distinction between physiological and psychological hunger [45].

\section{Environmental Cue Dependency}

To a degree, environmental food cues determine the desire for food, the onset of eating, and the magnitude of energy intake. According to the psychological principle known as Thorndike's Law of Effect [46], individuals tend to repeat and subsequently learn responses to signals that lead to tension reduction and the completion of motivated activity. Essentially, with regard to tension created by appetite, we are 'programmed' to immediately ingest whatever we see as edible ('a Tootsie Roll in the hand is almost a Tootsie Roll in the mouth') [47] and spit it later (if the piece is found to be unpalatable). Because of the limited information-processing 
capacity of the visual system, attention has the power to 'wrap around' a target signal, thereby excluding other cues that are potentially competing for interest [48], so that food cues narrow the focus of consciousness en route to a desirable item (into a sort of perceptual 'tunnel'). When confronted with a large number of food cues, such as is offered in a buffet dinner, even weight- (health-)conscious people may abandon the 'Take-the-Best' heuristic [49]. The point is that food may prompt a kind of 'environmental dependency syndrome'; when in a buffet environment, people simply maximize the amount of food on the plate in order to sample all they see $[50,51]$. Part of this environmental cue dependency may be associated with impulsivity. Experimentally, however, impulsive choice and cue hypersensitivity may dissociate [52], and probably should be managed separately.

Kennedy [53] noted that the principle of diversifying foods derives from the need to achieve nutritional adequacy. Perhaps that is how we tend to rationalize the need for assortment, but its biological and cognitive origins are worlds apart from our nutritional objectives. Is more choice in food always preferable? Is dietary assortment good or bad for weight gain? The answer is that a smorgasbord-style of dining is more likely to encourage eating in the absence of hunger [54]. The common phenomena of stimulus-specific satiety and novelty seeking [55] imply that monotonous diets are aversive. The amount of food people tend to select is a function of its diversity and the 'unit' in which food is offered [47, 56]. Sensory-specific satiety predicts that diversifying foods intensifies their hedonic ratings by causing oral or visual dishabituation [55]. Ultimately, the greater dietary variety is associated with increased body weight. By contrast, food sameness decreases its hedonic ratings by causing monotony. One might wonder whether limiting the visual food variety, particularly in people eating together, and maintaining this monotony over an extended time would be a viable technique in weight loss interventions [57].

The social component of eating in humans determines why vision may dominate olfaction. The shared experience of seeing other eaters and even reactions to their manners of enjoyment, their facial expression or body language, are irresistible triggers or, to the contrary, inhibitors of appetite. The way other participants behave has partial control over aspects of eating, such as its pace, the size of meal consumed, choices of food made, and length to termination [58]. A simpler human example of an adaptive social heuristic is to copy the choice of meal of someone who is more familiar with the restaurant [49].

In the absence of sight, the attractiveness of food or hurriedness of ingestion is anticipated to be significantly lessened. The research literature provides some support for this prediction. Blind people are forced to replace the missing information with other senses, but a creation of what might be called an acoustic or olfactory image of food space would be still deficient without visual food-related cues. The microstructure of eating behavior of the blind may seem similar to that of normal-sight controls. Only when controls were requested to eat with a blindfold, some differences emerged. When blindfolded, they ate $22 \%$ less food and had significantly shorter meal durations. Despite a smaller amount of food consumed, they reported a feeling of fullness identical to that after the larger serving ingested when seeing the meal, thereby suggesting that sight could have reduced the dependence on internal signals, and so eating blindfolded might be useful to those whose threshold for overeating is decided by the sight [59]. Alternatively, the benefit could be in eating slowly, increasing the likelihood of successful satiety signaling and avoiding the metabolic disadvantages of increased meal frequency.

\section{Homo Chronocentricus and Sleep}

Organisms exhibit cyclic variations in a variety of other essential functions, including reproduction, which in part is secondary to the daily alternation of darkness and light. The pathophysiology of obesity took a new turn with the recognition of sleep deficit as still another catalyst of obesity [60-63]. Homozygous Clock mutant mice, which have a greatly attenuated diurnal feeding rhythm, appear to be hyperphagic and obese and develop a metabolic syndrome of hyperleptinemia, hyperlipidemia, hepatic steatosis, hyperglycemia, and hypoinsulinemia $[64,65]$. Chronic sleep deficit is now believed to contribute to the visceral form of obesity that underlies the metabolic syndrome [66]. In Sweden, 6,400 men who were healthy at baseline were followed for almost 15 years. Difficulty in sleeping at baseline significantly predicted development of type 2 diabetes after controlling for a number of variables, such as age, BMI at screening, physical activity, family history of diabetes, smoking, social class, alcohol intake and others [67].

In mammals, the photoperiod is communicated by a primitive visual system distinct from the image-forming primary visual system; it projects via the retinohypothalamic tract to the 'master clock' located in the hypothalamic suprachiasmatic nucleus. However, our entire temporal identity is an interpretive framework within which we construe the world around us; our worldview has become hopelessly colored by 'chronocentrism' [68] when food availability becomes conditioned by other timed cues, i.e. when anticipatory behaviors and appraisal of the future rewards during foraging happen to be uncoupled from light/dark information.

\section{Physical Indolence}

Indolence is not synonymous to a conscious refusal to burn up energy through purposeful exercise. It is a non-volitional or subconscious activity, such as fidgeting or shifting in one's seat and spending time in purposeless moving (standing and ambulating) [69]. This involuntary activity is poorly characterized; the neuronal systems controlling it are virtually unknown. Recent studies by Levine and associates $[70,71]$ revealed that obese individuals were seated, on average, $2 \mathrm{~h}$ a day longer 
than were lean individuals. Posture allocation did not change when the obese individuals lost weight or when lean individuals gained weight, suggesting that it is biologically determined. It was predicted that the addition of non-volitional activity to daily behaviors might expend an additional $350 \mathrm{kcal} /$ day.

\section{The Fox or the Hedgehog Strategy?}

Diet and lifestyle changes are likely to remain the major tools of treatment for the near future, despite the fact that people are surprisingly deficient at predicting the degree to which their inclinations will last [72], and it is not unreasonable to be skeptical of the individuals' ability to keep up with a rigorous routine of dieting. Deservedly or not, these difficulties as well as a considerable investment of therapists' time have fueled anti-dieting sentiments in recent years [45]. Under the best of circumstances, therapeutic goals imply the need for numerous steps. These are:

- early identification of individuals at risk for developing obesity,

- early recognition of potential long-term metabolic problems,

- establishing endocrinological/neurochemical characteristics that covary with specific envirotypes,

- profiling potential responders and non-responders of scheduled clinical interventions,

- determining individual paths of pharmacotherapy and behavioral obesity management,

- predicting tolerance to pharmacotherapy as well as the possibility of side effects and noncompliance,

- initiating well-tolerated pharmaco-psychotherapy of affordable cost that impacts selective aspects of behavior.

Admittedly, those individualized behavioral maneuvers were relevant in the period of relative stability of the US populational weight (e.g., until 1980 [73]) when overweight could have been handled as sporadic episodes that were fought with individual cognitive-behavioral approaches (along with psychotherapy). However needed, they cannot be a strategy for successfully dealing with an epidemic when it is believed to have already afflicted over $60 \%$ of the population. In addition, obesity remains in the category of treatment-resistant disorders when no single treatment has been able to contain it [74]. The obesity epidemic has grown into a 'syndemic', a term coined in the early 1990s by the anthropologist Merrill Singer [reviewed in 75] to catalog diverse co-morbidities and environmental factors (e.g., diet, socioeconomic status, and 'toxic environments') in the context of their synergistic relations.

A famous British philosopher, Sir Isaiah Berlin [76], is credited with refreshing in his essay an ancient Greek parable: 'The fox knows many things, but the hedgehog knows one big thing.' In the present context, the miscellaneous knowledge of the fox would be synonymous to the term 'multifactorial'. The latter style of thinking is preferred when we feel that the 'one big thing' in managing a problem, such as obesity, is hardly possible, that more than one factor is in play and our explanation must be more nuanced such that a student or practicing clinician would be better prepared to confront individual behavioral or clinical problems. In this spirit, a recurrent trend in medicine is often to split rather than lump disease phenotypes into multiple components. With it, the tricks of 'fox knowledge' could presumably apply. The fox strategy is behind the temptation to split obesity into a number of components that might differ neuropsychologically and neurochemically.

The second paradigm affirms that awareness of the magnitude of obesity's social and economic costs could provide support for the magnitude of resources necessary for science to work towards development and implementation of a 'hedgehog plan' to contain this puzzling increase in the rates of obesity or to manage it preventively. Its major effort is delegated to the perinatal period and early childhood, since adult interventions in general have proven to be of limited effectiveness.

The frequency of diverse disorders in children born at low birth weight increased sharply in about 1980, but the cause of the condition is still poorly researched [77]. The prevalence of overweight among US children changed relatively little from the early 1960s through to 1980 . However, since 1980 it has increased sharply. This coincidence is suggestive. Collectively, pathological changes due to pre- or perinatal stressors were designated almost half a century ago as 'reproductive casualty' [78]. Nowadays, these early ideas evolved into the notion of latent 'functional teratogenesis' [79], which is actively discussed as part of the 'fetal' or 'Barker programming hypothesis' [80]. Prospective studies exploring this possibility are wanting, but the critical roles of intrauterine abnormalities (nutritional, neuroendocrine, hemodynamic, metabolic, and toxic) as well as a suboptimal early environment in the dysregulation of pathologies of adolescence or adulthood are increasingly recognized [reviewed in 81-85]. The major benefit in tracing the origin of the pathway to obesity from very early life periods is in the ability to itemize structural and molecular components of pathways that can predispose individuals to obesity in later life [86]. One example of the role of prenatal programming is that of rarefaction, which may be an early event in obesity, but could well be programmed prenatally or genetically. Compared with lean subjects, overweight/obese individuals appear to have $44 \%$ lower capillary density, suggesting that rarefaction could drive obesity via hypoxia and inflammation [87] cooperating in producing reactive oxygen species. The importance of both factors is in that they may be misattributed to obesity, but could be easily caused by pre- or perinatal pathology [88].

Harvey et al. [89] recently reproduced experimentally lymphatic vasculature dysfunction as a cause of adult-onset obesity by showing that functional inactivation of a single allele of the homeobox gene Proxl led to lymphedema with consequent hypertrophy or hyperplasia of adipocytes. At 6-12 
Fig. 1. General steps in obesity management based on alternative attributions of causality.

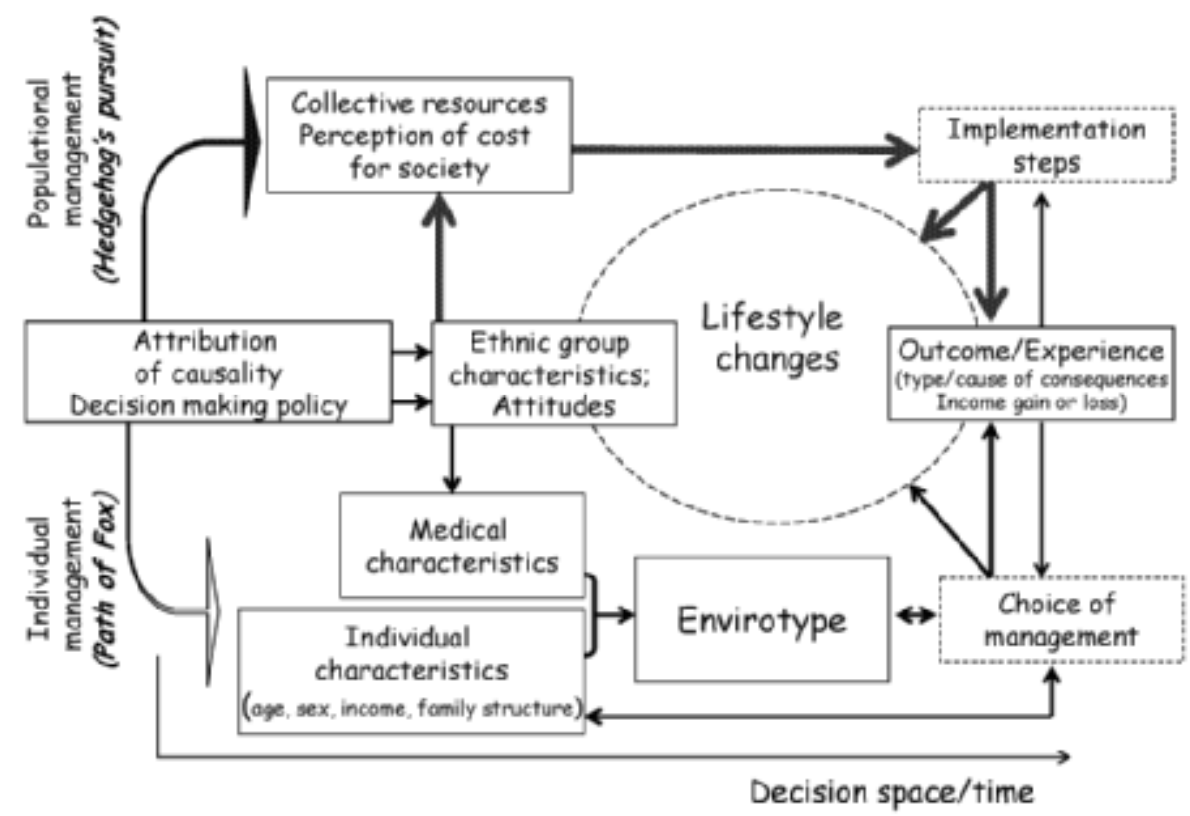

Successfully nurturing distressed neonates requires, in Ryle's [99] terminology, both 'knowledge-how' (procedural skills) as well as 'knowledge-that' (declarative knowledge). Even after successfully acquiring the former, caretakers may be guessing about the latter, and thus their default reaction may well be based on a 'false positive error', i.e. abandoning the search for the 'why' of an infant's distress and promptly initiating feeding, regardless of whether the infant's distress is hunger related or not [100]. In most cases, feeding will reliably reduce arousal and calm irritability. Consequently, a child learns to exploit a caretaker's conviction of accurate empathy to assure feeding ad libitum.

When mothers of obese children were compared with mothers of normal-weight children, the former showed a significant prevalence of the insecure attachment style (66.6 vs. $38.5 \%$ ). They idealized their own role as parents and the efficiency of the care (including feeding) they provide for their children [101]. In effect, such mothers add to obesity programming by reinforcing behaviors that pave the road to future 'stress-eating'.

These ideas have changed the field in several important ways. The major one is that the programming hypothesis has liberated obesity from the stigma of a disease of overindulgence; its 'hedgehog advantage' is in that it shifts the focus from the lifestyle of obese adults to that of their infancy and their caretakers. It sends the message that investing in preand perinatal care may be the best way of managing an epidemic of adult obesity. Finally, it gives hope for deliverance from a whimsical individualized one-on-one long-term care of obesity to the reliability of standardized care.

Figure 1 compares two paradigm streams in obesity management based on the attribution of causality and decisionmaking policy: individual management and population-based management. Both have strong and weak points; the question 
is not which one is possible, but which one best applies to the situation at hand. The steps are arranged in two streams (paradigms). The bottom stream treats obesity as a chronic individual problem, exploring individual paths to obesity [9]. The individual variables such as age, sex, occupation, education, income, ethnic origin, religion and the level of morbidity affect the eventual choices for behavioral or drug intervention. To emphasize the complexity of the bottom path, the flow of decision-making was marked to turn around at each step of the path, since in managing obesity, things can always go wrong, and commonly will. The distinction between a mere intermittent 'symptom' and a stable 'cognitive aberration' demanding a specific behavioral therapy is vague, but vital in practical implementations. An alternative model represented by the top stream proposes tackling obesity before it develops at the population level of decision-making and management. At a minimum, it denotes the need to work with expectant mothers, supporting healthy attachment, implementing strategies for maintaining healthy weight in preschoolers and other actions that begin before significant weight gain. The schematic does not ignore the 'Change lifestyle' that is shared by either strategy, such that the top path includes under this heading perinatal care, infant nutrition, as well as other traditional lifestyle amendments. The population-targeting approach is expected to be more transparent and, ultimately, cost effective. The 'Outcome/experience' button shown as a feedback station for both streams is established to empirically assess that claim. Evidence for greater cost and lower efficacy of the individualized approach would support shifting resources to the top-stream approach.

\section{Conclusions and Future Directions}

The word obesity is a recognized synecdoche, a figure of speech in which the whole may stand for a part: a particular cause (e.g., hyperphagic obesity), cosmetic problems, local expansion of adiposity (e.g. visceral obesity), genetics of obesity or 'obesity related diseases', for which no individual medical solution could be easily found. Public belief that adverse health events of overweight allegedly threaten to occur in the future is limited [73].

The behavioral syndrome logic of obesity aberrations might provide a neurobiological rationale for specifying relevant brain areas or molecular components, as well as their interconnections, to a range of biologically plausible conditions. A rigorous test of this possibility is still remote and requires specifying the model in more detail than is currently possible. No particular cerebral locus supports the reviewed scenarios that drive anticipatory behaviors, appraisal of current and future rewards, learning, and memory, circadian regulation of functions, locomotor activity, and vigilance. Said differently, the obesity-related neural network resides in so many areas of the brain that its neuronal network could be defined as 'utopia', meaning in the precise translation of the word (from Greek) 'no place'.

Its fundamentally 'utopic' (distributed) character has defied thus far the pharmacological mastery of obesity. It is a rare example of a field in which the gain in understanding of interactions of orexigenic and anorexigenic circuits has not been paralleled by innovative paradigms for managing obesity. No single drug against obesity is expected to be effective in most patients. Rather, varieties of drugs are needed to produce an efficacious cocktail. This would emphasize the utility of (cognitive) activity-directed drug disposition as 'pharmacopsychotherapy' advocated elsewhere $[102,103]$ when the notion of envirotype may be helpful in stratifying patient populations for clinical trials.

The principal characteristic of biological systems, and weight regulation is one of them, is that they are always multifarious [104]. A therapeutic hypothesis, to be practically useful when confronted by complexity, should consider every possibility that foretells the pathogenic trajectory of an organism in real life, because all possible pathological events may not be symptomatic or cannot be fully defined in terms of their probabilities. That accounts for the high cost and low efficacy of personalized care. In theory, pharmacotherapy of obesity faces the same dilemma. Yet, it is unrealistic to expect that, when designing a drug affecting central targets for the control of food intake and energy expenditure in humans, the pharmaceutical industry would conduct its clinical trials in patients with diverse cognitive profiles. That is why an admonition by Müller and Hebebrand [74] that the contemporary fear of the epidemic may create a therapeutic climate that, if implemented, would exceed the bounds of scientific and pragmatic possibilities is so pertinent. Given that medical costs are increasingly borne by governments, Neel [105] provocatively asked: 'To what extent should governments go to ensure that their citizenry lead lives more in keeping with their genetic endowment, presumably thereby decreasing medical costs?' (p. 18).

Obesity probably represents the final common pathway for a number of different processes. This perspective suggests that behavior modification along with diet, exercise and drug therapy would remain the province of the fox's trialand-error antiobesity measures and that, when it comes to an epidemic of obesity, the hedgehog strategy of early intervention may be more gainfully employed. If the list of pathological processes triggered in utero becomes self-perpetuating in adult life, the preventive path should be taken, for it focuses on the mediation of epigenetic effects that otherwise have the potential to be transmitted to more than the immediately succeeding generation. The proof of this approach, of course, lies in empirical validation of successful intervention through prospective longitudinal trials. As a first step, increased epidemiological investigation of perinatal and puerperal factors associated with adult obesity may provide a naturalistic experiment to shed light on promising strategies for future intervention trials. 


\section{Acknowledgements}

We are grateful to two anonymous reviewers for numerous useful suggestions. All remaining errors the reader might detect were produced without an outside help.

\section{Disclosure}

No financial interest has influenced the position taken in this manuscript.

\section{References}

1 Arner P: Obesity - a genetic disease of adipose tissue? Br J Nutr 2000;83(suppl 1):S9-S16.

$\checkmark 2$ Neel JV: Diabetes mellitus: a 'thrifty' genotype rendered detrimental by 'progress'? Am J Hum Genet 1962:14:353-362.

3 Hockaday TDR, Yajnik CS: Comment-to: Hales CN, Barker DJP (1992): Type 2 (non-insulin-dependent) diabetes mellitus: the thrifty phenotype hypothesis. Diabetologia 2003;35:595-601.

$\checkmark 4$ Prentice A, Rayco-Solon P, Moore S: Insights from the developing world: thrifty genotypes and thrifty phenotypes. Proc Nutr Soc 2005;64:153-156.

5 Bateson G: Mind and nature. A necessary unity. New York, Bantam Books, 1979.

6 Luszcz M: Introduction back to nurture: Cross-cultural research as a paradigm for understanding biocultural dynamics of cognitive ageing. Gerontology 2006;52:290-294.

7 Bandura A: Human agency in social cognitive theory. Am Psychol 1989;44:1175-1184.

8 Bandura A: Social foundations of thought and action: A social cognitive theory. Englewood Cliffs, Prentice Hall, 1986.

9 Blundell J, Cooling J: Routes to obesity: phenotypes, food choices and activity. Br J Nutr 2000;20: S33-S38.

10 Chisholm JS, Burbank VK: Evolution and inequality. Int J Epidemiol 2001;30:206-211.

11 Strotz RH: Myopia and inconsistency in dynamic utility maximization. Rev Econ Stud 1956;23:165180.

12 Stephens DW, Kerr B, Fernandez-Juricic E: Impulsiveness without discounting: the ecological rationality hypothesis. Proc Biol Sci 2004;271:2459-2465.

13 Stephens DW: Discrimination, discounting and impulsivity: a role for an informational constraint. Philos Trans R Soc Lond B Biol Sci 2002;357:15271537.

14 Cabanac M, Guillaume J, Balasko M, Fleury A: Pleasure in decision-making situations. BMC Psychiatry 2002;2:7.

15 Goodman A: Addiction: definition and implications. Br J Addict 1990;85:1403-1408.

16 Walker MB: The psychology of gambling. Oxford, Pergamon, 1992.

17 Davis C: Psychobiological traits in the risk profile for overeating and weight gain. Int J Obes 2009;33 (suppl 2):S49-S53.

18 Davis C, Levitan R, Muglia PBC, Kennedy JL: Decision-making deficits and overeating: a risk model for obesity. Obes Res 2004;12:929-935.

19 Davis C, Levitan RD, Muglia P, Bewell C, Kennedy JL: Decision-making deficits and overeating: a risk model for obesity. Obes Res 2004;12:929-935.

20 Pignatti R, Bertella L, Albani G, Mauro A, Molinari E, Semenza C: Decision-making in obesity: a study using the gambling task. Eat Weight Disord 2006;11:126-132.

-21 Bechara A, Damasio H, Tranel D, Damasio AR: Deciding advantageously before knowing the advantageous strategy. Science 1997;275:1293-1295.
22 Maia TV, McClelland JL: A reexamination of the evidence for the somatic marker hypothesis: what participants really know in the Iowa gambling task. Proc Natl Acad Sci U S A 2004;101:16075-16080.

23 Westenhöfer J: Self-control, stimulus control, relapse prevention. Behavior therapy helps in weight reduction. MMW Fortschr Med 2001;143:43-45.

24 Blundell JE: What food do people habitually eat? A dilemma for nutrition, an enigma of psychology. Am J Clin Nutr 2000;71:3-5.

25 Bandini LG, Must A, Cyr H, Anderson S, Spadano JL, Dietz WH: Longitudinal changes in the accuracy of reported energy intake in girls $10-15 \mathrm{y}$ of age. Am J Clin Nutr 2003;78:480-484.

26 Styne DM: Obesity in childhood: what's activity got to do with it? Am J Clin Nutr 2005;81:337-338.

27 Ardelt-Gattinger E, Lechner H: [Psychological aspects of bariatric surgery][Article in German]. Zentralbl Chir 2002;127:1057-1063.

28 Yon B, Johnson RK, Harvey-Berino J, Gold BC: The use of a personal digital assistant for dietary self-monitoring does not improve the validity of self-reports of energy intake. J Am Diet Assoc 2006; 106:1256-1259.

29 McKay R: The evolution of misbelief adaptation and representation. Adaptation and representation. Newsletter 2007, http://www.interdisciplines. org/adaptation/papers/4.

30 Lara JJ, Scott JA, Lean ME: Intentional mis-reporting of food consumption and its relationship with body mass index and psychological scores in women. J Hum Nutr Diet 2004;17:209-218.

31 Herman CP, Polivy J: A boundary model for the regulation of eating; in: Stunckard AB, Stellar E (eds): Eating and its disorders. New York, Raven Press, 1984, pp 141-156.

32 Mitchell GL, Brunstrom JM: Everyday dietary behaviour and the relationship between attention and meal size. Appetite 2005;45:344-455.

33 Wegner DM: The mind's best trick: How we experience conscious will. Trends Cogn Sci 2003;7:65-69.

34 Quinn S: The Washington Post 1994, November 20, Sect. c1.

35 Andreou C: Environmental damage and the puzzle of the self-torturer. Philos Public Aff 2006;34:95108.

36 Rosenbaum M, Leibel RL, Hirsch J: Obesity. N Engl J Med 1998;337:396-407.

37 Weinstein N: Optimistic biases about personal risks. Science 1989;246:1232-1233.

38 Glicksohn J, Myslobodsky M: Timing the future: The case for a time-based prospective memory. London, World Science, 2006.

39 Blundell JE, Gillett A: Control of food intake in the obese. Obes Res 2001;9(suppl 4):263S-270S.

40 Lyke JA, Spinella M: Associations among aspects of impulsivity and eating factors in a nonclinical sample. Int J Eat Disord 2004;36:229-233.

41 Nederkoorn C, Braet C, Van Eijs Y, Tanghe A, Jansen A: Why obese children cannot resist food: the role of impulsivity. Eat Behav 2006;7:315-322.
2 Ryden A, Sullivan MTJ, Karlsson J, Lindroos AK, Taft C: A comparative controlled study of personality in severe obesity: a 2-y follow-up after intervention. Int J Obes Relat Metab Disord 2004;28:1485-1493.

43 Nederkoorn C, Smulders FT, Havermans RC, Roefs A, Jansen A: Impulsivity in obese women. Appetite 2006;47:253-256.

44 Tuomisto T, Tuomisto MT, Hetherington M, Lappalainen R: Reasons for initiation and cessation of eating in obese men and women and the affective consequences of eating in everyday situations. Appetite 1998;30:211-222.

45 Lowe MR, Levine AS: Eating motives and the controversy over dieting: eating less than needed versus less than wanted. Obes Res 2005;13:797-806.

46 Nevin J: Stimulus-response bonds. J Exp Anal Behav 1999;72:447-450.

47 Geier AB, Rozin P, Doros G: Unit bias. A new heuristic that helps explain the effect of portion size on food intake. Psychol Sci 2006;17:521-525.

48 Moran J, Desimone R: Selective attention gates visual processing in the extrastriate cortex. Science 1985;229:782-784.

49 Hutchinson JM, Gigerenzer G: Simple heuristics and rules of thumb: where psychologists and behavioural biologists might meet. Behav Processes 2005;69:97-124.

50 Myslobodsky M: Gourmand savants and environmental determinants of obesity. Obes Rev 2003;4: 121-128.

51 Nasser JA, Gluck ME, Geliebter A: Impulsivity and test meal intake in obese binge eating women. Appetite 2004;43:303-307.

52 Olmstead MC, Hellemans KG, Paine TA: Alcoholinduced impulsivity in rats: an effect of cue salience? Psychopharmacology (Berl) 2005:1-8.

53 Kennedy E: Dietary diversity, diet quality, and body weight regulation. Nutr Rev 2004;62:S78-S81.

54 Faith MS, Berkowitz RI, Stallings VA, Kerns J, Storey M, Stunkard AJ: Eating in the absence of hunger: A genetic marker for childhood obesity in prepubertal boys? Obesity 2006;14:131-138.

55 Rolls BJ, Rolls ET, Rowe EA, Sweeney K: Sensory specific satiety in man. Physiol Behav 1981;27:137142.

56 Raynor H, Epstein L: Dietary variety, energy regulation, and obesity. Psychol Bull 2001;127:325-341.

57 Raynor H, Niemeier HM, Wing RR: Effect of limiting snack food variety on long-term sensoryspecific satiety and monotony during obesity treatment. Eat Behav 2006;7:1-14.

58 Levitsky D: The non-regulation of food intake in humans: hope for reversing the epidemic of obesity. Physiol Behav 2005;86:623-632.

59 Linne Y, Barkeling B, Rossner S, Rooth P: Vision and eating behavior. Obes Res 2002;10:92-95.

60 Flier JS, Elmquist JK: A good night's sleep: future antidote to the obesity epidemic? Ann Intern Med 2004;141:885-886.

61 Bass J, Turek FW: Sleepless in America: A pathway to obesity and the metabolic syndrome? Arch Intern Med 2005;165:15-16. 
62 Tjepkema M: Insomnia. Health Rep 2005;17:9-25.

-63 Vorona RD, Winn MP, Babineau TW, Eng BP, Feldman HR, Ware JC: Overweight and obese patients in a primary care population report less sleep than patients with a normal body mass index. Arch Intern Med 2005;165:25-33.

64 Turek FW, Joshu C, Kohsaka A, Lin E, Ivanova G, McDearmon E, Laposky A, Losee-Olson S, Easton A, Jensen DR, Eckel RH, Takahashi JS, et al.: Obesity and metabolic syndrome in circadian clock mutant mice. Science 2005;308:1043-1045.

65 Oishi K, Atsumi G, Sugiyama S, Kodomari I, Kasamatsu M, Machida K, et al.: Disrupted fat absorption attenuates obesity induced by a high-fat diet in Clock mutant mice. FEBS Lett 2006;580:127-130.

66 Penev P: Sleep deprivation and energy metabolism: to sleep, perchance to eat? Curr Opin Endocrinol Diabetes Obes 2007;14:374-381.

67 Nilsson PM, Roost M, Engstrom G, Hedblad B, Berglund G: Incidence of diabetes in middle-aged men is related to sleep disturbances. Diabetes Care 2004;27:2464-2469.

68 de Rosnay J: The macroscope: A new world scientific system. New York, Harper and Row Publishers, 1979.

69 Kotz CM: Integration of feeding and spontaneous physical activity: role for orexin. Physiol Behav 2006; 88:294-301.

70 Levine JA, Kotz CM: NEAT - non-exercise activity thermogenesis - egocentric and geocentric environmental factors vs. biological regulation. Acta Physiol Scand 2005;184:309-318.

71 Levine JA, Lanningham-Foster LM, McCrady SK, Krizan AC, Olson LR, Kane PH, et al.: Interindividual variation in posture allocation: Possible role in human obesity. Science 2005;307:584-586.

72 Rozin P, Hanko K, Durlach P: Self-prediction of hedonic trajectories for repeated use of body products and foods: poor performance, not improved by a full generation of experience. Appetite 2006; 46:297-303.

73 Flegal KM: Epidemiologic aspects of overweight and obesity in the United States. Physiol Behav 2005;86: 599-602.

74 Müller MJ, Hebebrand J: Should we really treat every obese individual? Obes Facts 2008;1:287-291.

75 Schabath MB, Delclos GL, Martynowicz MM, Greisinger $\mathrm{AJ}, \mathrm{Lu} \mathrm{C}, \mathrm{Wu} \mathrm{XF}$, et al.: Opposing effects of emphysema, hay fever, and select genetic variants on lung cancer risk. Am J Epidemiol 2005;161:412422.
76 Berlin I: The hedgehog and the fox. Chicago, Elephant Paperbacks, 1993

77 Stanley R, Blair E, Alberman E: Cerebral palsies: epidemiology and causal pathways. Cambridge, Cambridge University Press, 2000.

78 Pasamanick B, Knobloch H: Brain damage and reproductive casualty. Am J Orthopsychiatry 1960;30: 98-305.

79 Plagemann A: Fetal programming and functional teratogenesis: on epigenetic mechanisms and prevention of perinatally acquired lasting health risks. J Perinat Med 2004:32:297-305.

80 Barker DJP: Mothers, babies and disease in later life. London, BMJ Publishing, 1994.

81 Dietz W: Periods of risk in childhood for the development of adult obesity - what do we need to learn? J Nutr 1997;127:1884S-1886S.

82 Lau C, Rogers J: Embryonic and fetal programming of physiological disorders in adulthood. Birth Defects Res C Embryo Today 2004;72:300-312.

83 McMillen IC, Robinson JS: Developmental origins of the metabolic syndrome: prediction, plasticity, and programming. Physiol Rev 2005;85:571-633.

84 Feinberg AP: Phenotypic plasticity and the epigenetics of human disease. Nature 2007;447:433-440

85 Godfrey KM, Lillycrop KA, Burdge GC, Gluckman PD, Hanson MA: Epigenetic mechanisms and the mismatch concept of the developmental origins of health and disease. Pediatr Res 2007;61:5R-10R

86 Muhlhausler BS, Adam CL, McMillen IC: Maternal nutrition and the programming of obesity: The brain. Organogenesis 2008;4:144-152.

87 Pasarica M, Sereda OR, Redman LM, Albarado DC, Hymel DT, Roan LE, Rood JC, Burk DH, Smith SR: Reduced adipose tissue oxygenation in human obesity: evidence for rarefaction, macrophage chemotaxis, and inflammation without an angiogenic response. Diabetes 2009;58:718-725.

88 Muhlhausler B, Smith SR: Early-life origins of metabolic dysfunction: role of the adipocyte. Trends Endocrinol Metab 2009;20:51-57.

89 Harvey NL, Srinivasan RS, Dillard ME, Johnson NC, Witte MH, Boyd K, et al.: Lymphatic vascular defects promoted by Prox1 haploinsufficiency cause adult-onset obesity. Nat Genet 2005;37:1072-1081.

90 Stappenbeck TS, Hooper LV, Gordon JI: Developmental regulation of intestinal angiogenesis by indigenous microbes via Paneth cells. Proc Natl Acad Sci U S A 2002;99:15451-15455.

91 Caicedo RA, Schanler RJ, Nan L, Neu J: The developing intestinal ecosystem: implications for the neonate. Pediatr Res 2005;58:625-628.
92 Backhed F, Manchester JK, Semenkovich CF, Gordon JI: From the cover: Mechanisms underlying the resistance to diet-induced obesity in germfree mice. Proc Natl Acad Sci USA 2007:104:979_ 984.

93 Lederberg J: Infectious history. Science 2000;288: 287-293.

94 Szyf M, Weaver I, Meaney M: Maternal care, the epigenome and phenotypic differences in behavior. Reprod Toxicol 2007;24(1):9-19.

95 Rüedi-Bettschen D, Pedersen EM, Feldon J, Pryce CR: Early deprivation under specific conditions leads to reduced interest in reward in adulthood in Wistar rats. Behav Brain Res 2005;156:297-310.

96 Mathé A, Husum H, Khoury AE, JiménezVasquez P, Gruber SH, Wörtwein G, Nikisch G Baumann P, Agren H, Andersson W, Södergren A, Angelucci F: Search for biological correlates of depression and mechanisms of action of antidepressant treatment modalities. Do neuropeptides play a role? Physiol Behav. 2007;92:226-231.

97 Joseph R: The evolution of sex differences in language, sexuality, and visual-spatial skills. Arch Sex Behav 2000;29:35-66.

98 Baldaro B, Balsamo A, Caterina R, Fabbrici C, Cacciari E, Trombini G: Decoding difficulties of facial expression of emotions in mothers of children suffering from developmental obesity. Psychother Psychosom 1996;65:258-261.

99 Ryle G: The concept of mind. London, Hutchinson, 1949.

100 Bruch H: Eating disorders: anorexia nervosa and the person within. London, Routledge and Kegan, 1974.

101 Trombini E, Baldaro B, Bertaccini R, Mattei C, Montebarocci O, Rossi N: Maternal attitudes and attachment styles in mothers of obese children. Percept Mot Skills 2003;97:613-620.

102 Myslobodsky M, Weiner M: Pharmacologic implications of hemispheric asymmetries. Life Sci 1976;19:1467-1478.

103 Myslobodsky M, Weiner M: Pharmacopsychotherapy and aberrant brain laterality; in: Myslobodsky M (ed): Hemisyndromes: Psychobiology, neurology, psychiatry. New York, Academic Press, 1983, p 447.

104 Sole R, Goodwin B: Signs of life: how complexity pervades biology. New York, Basic, 2000

105 Neel JV: Some ethical issues at the population level raised by 'soft eugenics', euphenics, and isogenics. Hum Hered 2000;50:14-21. 